\title{
"ИСАТЕЛ":
}

\section{штрихи к портрету компании}

л.Павлова

DOI: $10.22184 / 2070-8963.2019 .85 .8 .20 .21$

Созданная в 2003 году по инициативе ряда стран-членов МОКС ИНТЕРСПУТНИК компания "Исател" свыше 10 лет выступала как системный интегратор спутниковой связи, а с конца 2015 года вошла в пул российских операторов спутниковой связи Ка-диапазона. Какие задачи компания решает сегодня и каковы ее планы на будущее?

\section{НЕМНОГО ИСТОРИИ}

ОоО "Исател" - российская "дочка" Международной организации космической связи (МОКС) ИНТЕРСПУТНИК, основанной в 1971 году и включающей сегодня 26 стран. Изначально МОКС занималась предоставлением спутникового ресурса на космических аппаратах СССР. Со временем стало понятно, что для участников и членов Организации необходимо реализовывать также комплексные проекты, в которые входит как предоставляемая ИНТЕРСПУТНИКОМ спутниковая емкость, так и наземная часть - земные станции спутниковой связи (ЗССС), каналы связи. Для этого потребовалось организовать юридическое лицо, получить необходимые лицензии - и таким образом в 2003 году был рожден системный интегратор ООО "Исател".

В 2015 году он стал также оператором спутниковой связи Ка-диапазона. Комментируя поворот компании к операторской деятельности в Ка-диапазоне, ее генеральный директор Игорь Заболотный отмечает: "У наших партнеров, в первую очередь ФГУП "Космическая связь", есть емкость в Ка-диапазоне, которая предназначена для того, чтобы предоставлять прежде всего физическим лицам доступ в интернет на тех территориях, которые пока не охвачены наземными сетями. Поэтому было принято решение о выходе на массовый рынок".

\section{ТрУдНостИ НовоГО РЫНКА}

Но, как и другие российские операторы спутниковой связи Ка-диапазона, в этом сегменте рынка "Исател" столкнулся с проблемой: конечный клиент далеко не всегда понимает, в чем разница между работой в Кu- и Ка-диапазоне, и считает, что спутниковая связь - это дорого и медленно. Потенциальному пользователю нужно разъяснять, какие преимущества дает Ка-диапазон, почему абонентский комплект дешевле и прочие детали. В частности, для популяризации этой идеи по просьбе таких же операторов (их около десятка) "Исател" создал и поддерживает сайт KA-BAND.info.

Несмотря на усилия по совместному продвижению и популяризации услуг спутниковой связи в Ка-диапазоне, прирост абонентов сетей операторов происходит значительно медленнее, чем ожидалось. Это общая проблема, связанная с дороговизной абонентского оборудования. Для ее решения необходимо снизить стоимость "входного билета" для потенциального клиента - либо за счет предоставления скидки на оборудование, либо за счет переноса части стоимости оборудования в абонентскую плату. При этом приходится учитывать, что в России, по общим оценкам, стоимость доступа в интернет и по фиксированным, и по мобильным сетям одна из самых низких в мире. Рынок находится под жестким давлением операторов, которые занимаются фиксированным доступом исключительно благодаря федеральным программам, которые сейчас реализуются. В такой конкурентной среде операторам VSAT очень тяжело бороться за выживание.

С поиском потенциальных абонентов спутниковой связи Ка-диапазона сложилась нетривиаль ная ситуация: самая большая трудность состоит в том, чтобы довести до них информацию об услуге. "Действующая госпрограмма обеспечения широкополосного доступа, которую реализует "Ростелеком", даст ШПд по ВОЛС населенным пунктам с численностью населения больше 
250 человек, - констатирует И.Заболотный. - Наша аудитория, на мой взгляд, находится как раз там, где количество жителей в населенных пунктах составляет менее 250 человек, и они не входят сейчас ни в одну из ФЦП. По крайней мере, на данном этапе развития телекоммуникаций в нашей стране. Населенных пунктов с числом жителей от одного человека до 250, по разным оценкам, насчитывается не один десяток тысяч. Расположены они во всех федеральных округах России, от Московской области до самых удаленных регионов страны. Они, как правило, не имеют доступа в интернет. Значит, нужно искать другие способы доведения информации".

\section{АКЦЕНТ НА СИСТЕМНУЮ ИНТЕГРАЦИЮ}

Сегодня в бизнесе "Исатела" услуги Ка-диапазона это скорее имиджевая, чем системная часть дохода. Кроме того, доля услуг по предоставлению каналов спутниковой связи в последние годы снижается в общей структуре выручки компании. "Это общая тенденция рынка, - поясняет И.Заболотный. - В последние годы владельцы спутниковой емкости выбрали для себя стратегию непосредственной работы с конечным пользователем - и все меньше нуждаются в посредниках для того, чтобы работать с конечными клиентами, юридическими и физическими лицами. Этот сегмент рынка, где было достаточно свободно некоторое время назад, сейчас для компаний, которые предоставляют спутниковые емкости и находятся между владельцами КА и конечными пользователями, постоянно сужается". Поэтому два года назад в "Исател" было принято решение о возврате к стратегии системной интеграции, и сегодня основной бизнес компании - модернизация сетей связи конечных пользователей, строительство сетей связи для конечных пользователей и обслуживание сетей связи конечных пользователей. При этом клиентская база с каждым годом прирастает новыми заказчиками.

Один из новых клиентов - социальная служба Мадагаскара, для которой "Исател" построил сеть спутниковой связи. "Исател" осуществляет проектирование, доставку оборудования, монтаж оборудования, ввод сети в эксплуатацию по тем нормативам, которые установлены в странах, где компания работает, выступая как подрядная организация по строительству. При реализации подобных проектов МОКС ИНТЕРСПУТНИК оказывает немалую помощь своей "дочке", информационно взаимодействуя с заказчиком и предоставляя спутниковую емкость. "В случае с Мадагаскаром мы взаимодействуем через
ИНТЕРСПУТНИК с азербайджанским оператором "Азеркосмос", и наше преимущество состоит как раз в том, что можем работать через любую спутниковую емкость, тем более, если она принадлежит стране-члену МОКС. У ИНТЕРСПУТНИКА налажен очень плотный информационный обмен с разными странами, запросы в МОКС поступают со всего мира", - поясняет И.Заболотный.

Соответственно, зарубежных клиентов у такого системного интегратора не меньше, чем российских. А в России компания чувствует себя вполне уверенно. В нынешнем году знаковым для "Исатела" стала победа в двух тендерах крупнейшего российского банка, с которым заключены контракты на модернизацию сети спутниковой связи этого банка и на ее техническое обслуживание. Можно отметить, что "Исател" обошел четырех претендентов, также подавших заявки на участие в конкурсах.

Оставаться первой в своей области компетенций компания намерена и впредь.

\section{ОСТАВАТЬСЯ ПЕРВЫМИ}

На пороге больших перемен на рынке спутниковой связи (снижение в доходах владельцев космических аппаратов доли традиционных услуг и рост доли новых сервисов) каждый игрок ищет перспективные бизнес-модели, которые позволят не только встроиться в новые реалии рынка, но и развивать бизнес. "Одна из наших задач - подготовиться к такого рода изменениям рынка, - отмечает И.Заболотный. - Бизнес "Исател" строится на том, чтобы предоставлять клиенту услуги, которые соответствуют его ожиданиям. Это не просто спутниковая емкость, а канал спутниковой связи плюс оконечное оборудование - с высокой эффективностью использования полосы. Мы это делаем сегодня. А завтра будем предлагать клиентам полный комплекс решений, включая предоставление недорогих спутниковых модемов вместе с каналами связи. В настоящее время мы работаем с одним из отечественных производителей, который завершил разработку такого модема, - и я надеюсь, что в скором времени предложим рынку уже вполне адекватную модель, которая позволит нашим заказчикам оптимизировать свой бизнес с точки зрения расходов, стоимости технического обслуживания сети за счет того, что мы будем предоставлять такие модемы нашим клиентам в пользование в составе услуги. Очень важно, что недорогое оконечное оборудование отечественного производства даст нам определенные преимущества на конкурсных процедурах. Мы постоянно ищем пути, которые позволят нам быть и оставаться первыми". 